Artigo / Article 





\title{
A civilização maia: contextualização historiográfica e arqueológica
}

\author{
Alexandre Guida NAVARRO *
}

\begin{abstract}
Resumo: Este artigo versa sobre a contextualização historiográfica e arqueológica da civilização maia. O intuito é traçar um perfil das primeiras explorações nos sítios arqueológicos, observar a construção do conhecimento criada acerca das primeiras informações obtidas pela Arqueologia, além das diversas vinculações das pesquisas empreendidas em relação aos contextos históricos de sua época e as teorias utilizadas atualmente pelos maístas.
\end{abstract}

Palavras-chave: Maias; Cultura material, Historiografia, México.

\section{Localização geográfica}

A região em que se desenvolveu a civilização maia ${ }^{1}$ corresponde ao que é hoje a península do Yucatán, no México, englobando os atuais Estados de Campeche, Tabasco, Chiapas, Iucatã e Quintana Roo; as terras baixas e altas da Guatemala; Belize; a porção ocidental de Honduras e El Salvador, reunindo territórios que pertencem à área denominada Mesoamérica (figura 1. Mapa de Mesoamérica. Em Grube e Martin, 2002: 10) ${ }^{2}$. A área maia, situada na confluência entre a América do Norte e a América Central, apresenta no aspecto geográfico, duas grandes divisões, comumente designadas de Terras Altas e Terras Baixas, subdividindo-se nas regiões meridional, central e setentrional. A

* Doutor em Antropologia/Arqueologia - Universidade Nacional Autônoma do México - Associado ao Núcleo de Estudos Estratégicos (NEE/UNICAMP). Email: altardesacrificios@yahoo.com.br 
área meridional compreende essencialmente as Terras Altas da Guatemala, formada por uma cadeia montanhosa de origem vulcânica, cujos picos mais altos alcançam 4000 metros de altura. Possui um clima quente e úmido, estendendo-se da porção oriental de Chiapas, no México, até El Salvador. Esta região é regada por dois sistemas fluviais principais. O primeiro forma o rio Motágua, que nasce no atual Departamento de Quiché, na Guatemala, corre em sentido leste-nordeste e desemboca no Golfo das Honduras, costa do Caribe; o segundo compreende o rio Usumacinta, formado por três afluentes principais: o Pasión, Chixoy ou Salinas e o Lacantún, desembocando no Golfo do México através de vários braços. O Usumacinta e seus tributários formam a via fluvial de maior importância na área maia. Os centros de povoamento nas terras altas concentram-se em vales que se elevam a mil metros acima do nível do mar. Esta região apresenta dois lagos, o Amatitlán, próximo da cidade da Guatemala e o lago Atitlán, no Departamento de Sololá. Esta zona meridional, apesar da fertilidade, dos recursos naturais e do papel determinante que desempenhou durante as fases formativas da civilização maia, apresentou um número de centros de povoamento bem inferior ao das Terras Baixas.

As Terras Baixas situam-se na maior parte abaixo de 600 metros de altitude, raramente ultrapassando os 100 ou 200 metros. Dividem-se em duas partes: as terras Baixas do Sul, ou Área Central, cobertas quase que exclusivamente por uma floresta tropical mais ou menos densa e muito úmida, que se prolonga desde a planície costeira de Tabasco, no Golfo do México, até Belize e Honduras, no litoral do Mar do Caribe e passando pelo Petén, no norte da Guatemala. Já as Terras Baixas do Norte, ou Área Setentrional, englobando praticamente toda a península do Iucatã, caracterizam-se por uma grande formação calcária e são quase que exclusivamente desprovidas de cursos d'água superficiais; em direção noroeste, o clima torna-se progressivamente árido. 


\section{Periodização}

Tradicionalmente, os arqueólogos dividiram a História maia em três períodos principais: Pré-Clássico (800 a.C. a 300 d.C.), Clássico (300 d.C. a 900 d.C.), Pós-Clássico (900 d.C. a 1520 d.C.).

Cada um destes períodos possui estilos distintos de cerâmica e arquitetura. O período Clássico tem sido tradicionalmente visto como o auge da civilização maia, devido à imponência de seus palácios e templos, às estelas - monumentos verticais onde foram registradas inscrições hieroglíficas -, além de sua elaborada cerâmica policrômica. O período Pré-Clássico teria sido formado por vilas rurais modestas e desprovido de realizações arquitetônicas tão expressivas quanto às do Clássico. Já o PósClássico foi um período de decadência cultural e artística. Este modelo, que ainda é muito difundido, apresenta muitas discrepâncias. No intuito de reformular, e não refutar, os dados apresentados pelos estudiosos ao longo da primeira metade do século $\mathrm{XX}$, o esforço dos arqueólogos hoje é a reinterpretação destas informações a fim de se buscar uma periodização mais adequada.

Segundo Jeremy A. Sabloff (1994), os primeiros arqueólogos enfatizaram os aspectos elitistas da civilização maia, como os papéis dos sacerdotes e governantes na sociedade. Esta preocupação com a classe alta direcionou as pesquisas arqueológicas, uma vez que existia uma acentuada demanda pelos museus de materiais finos para sua exposição, justamente os produtos da cultura elitista. Durante a Segunda Guerra Mundial, os resultados dos contínuos trabalhos de campo estabeleceram um modelo de como a civilização maia havia se estruturado, baseado também nas realizações da elite.

Este modelo foi exposto pelo arqueólogo J. Eric S. Thompson (1927). Suas concepções, até muito recentemente, exerceram uma influência muito grande nos estudos dos arqueólogos maianistas. Entretanto, há três décadas, pesquisas têm demonstrado que muitos dos discursos do "modelo tradicional" são passíveis de crítica (Sabloff, 1971; Brunhouse, 1971; Becker, 1979; Hammond, 
1983; Robertson e Freidel, 1986; Tainter, 1988; Berlo e Diehl, 1989; Sabloff y Tourtellot, 1991; Sabloff e Henderson, 1993; Culbert, 1994).

Estes erros vieram, em parte, dos resultados de limitados dados de trabalho de campo. A obtenção de novos dados sobreveio do desenvolvimento de novas técnicas, tanto de campo quanto de laboratório, além de informações oriundas de metodologias inovadoras, como a análise em terminais de computador, o uso de microscópios binoculares, imagens de satélite, levantamento cartográfico feito com instrumentos a laser e avançadas técnicas químicas que concretizaram e forneceram novos tipos de informação.

Além disso, uma ampla escala de esforços tem tornado os procedimentos dos arqueólogos mais rigorosos, encorajando os pesquisadores a reinterpretar os dados já existentes e possibilitando novas evidências daquilo que havia sido ignorado. Além dessa bateria de análises técnicas sofisticadas e agora disponíveis, surgem novas concepções para interpretar o passado e novos métodos e procedimentos para estudar os vestígios arqueológicos, frutos de uma série de transformações na Arqueologia ao longo do tempo.

\section{As primeiras explorações: histórico}

A Arqueologia maia foi inaugurada com duas explorações realizadas entre os anos de 1839 e 1841 pelo diplomata e advogado norte-americano John Stephens e o arquiteto inglês Frederick Catherwood. Os resultados destas explorações renderam duas obras redigidas subseqüentemente Incidents of Travel in Central America, Chiapas and Yucatán (1841) e Incidents of Travel in Yucatán (1843).

Recém chegado do Egito e Mediterrâneo e com o sucesso das obras Incidents of Travel in Egypt, Arabia Petrae and the Holy Land e Incidents of Travel in Greece, Turkey, Russia and Poland (1838), Stephens logo atraiu a atenção do público para as antigas civilizações da América Central. Suas descrições das ruínas maias são meticulosas e ricas em detalhes. O mesmo ocorre com 
Catherwood, cujos desenhos estão desprendidos de todo o excesso artístico e fantasioso que prevalecia em seu tempo. Seus desenhos enfatizaram uma natureza exótica da civilização maia, focada nos templos mais visíveis e nos monumentos de modo geral. Esta visão que busca unir a exuberância do meio-ambiente e as complexas estruturas arquitetônicas tornou-se vigente não somente no século XIX, mas em grande parte do pensamento arqueológico deste século.

Seguindo os passos de Stephens e Catherwood, muitos estudiosos no século XIX deram continuidade às descrições e mapeamento de sítios arqueológicos maias, incluindo Alice e Augustus Le Plongeon, Desiré Charnay, Edward H. Thompson e Teobert Maler, cujas observações ainda se centravam nos palácios, templos e monumentos esculpidos. De todos estes estudiosos, o que mais contribuiu para o estabelecimento de uma Arqueologia maia foi o inglês Alfred P. Maudslay, cujas explorações iniciaramse em 1881. Sua contribuição maior veio da confecção, em grande detalhe, de plantas de inúmeros sítios arqueológicos, desenhando e fotografando as maiores estruturas destes sítios.

Os resultados de seu trabalho foram publicados nos volumes 1 a 4 da obra Biologia Centrali-Americana (Londres, 1889-1902). As primeiras escavações em larga escala ocorreram no sítio arqueológico de Copán, Honduras, empreendidas pelo Peabody Museum da Universidade de Harvard, na década de 1890. Os trabalhos proporcionaram uma visão mais ampla deste sítio, evidenciando suas estruturas, como templos, estelas e praças abertas. Os primeiros trabalhos de síntese sobre a Arqueologia maia foram publicados entre 1900 e 1930 por pesquisadores como J. Eric Thompson (1927, 1930), Herbert Spinden (1913), Thomas Gann (1931) e Thomas Joyce (1914). Suas informações provieram de descrições baseadas em inscrições hieroglíficas encontradas em diferentes sítios de seqüência histórica no norte das terras baixas do Iucatã e registradas nos documentos do período da Conquista.

As característias da antiga civilização maia que se dispersaram mundialmente surgiram nos últimos anos do século XIX e se concretizaram até o final da Segunda Guerra Mundial, 
período este em que se desenvolveu o modelo maia tradicional. $\mathrm{O}$ palco para o estabelecimento das idéias propostas por este modelo foi o sítio arqueológico de Uaxactún, localizado no sul das terras baixas, cujos trabalhos de escavação foram dirigidos por Oliver Ricketson e A. Ledyard Smith, da Carnegie Institution of Washington, entre os anos de 1926 e 1937 (Smith, 1950). Seus trabalhos estabeleceram uma determinação seqüencial e cronológica, através da cerâmica, para os sítios arqueológicos maias e que permanecem até hoje. A Carnegie Institution ainda conduziu um projeto de escavação em Mayapán, sítio do PósClássico Tardio, localizado no norte do Iucatã, entre os anos de 1949 e 1955, onde se realizou um mapeamento intensivo deste centro urbano, que esteve cercado por fortificações além de todas as residências do sítio (Pollock et al. 1962).

\section{O modelo tradicional da civilização maia}

O modelo tradicional maia foi elaborado do final do século XIX a meados do XX por diversos arqueólogos que adentraram a floresta tropical da América Central em busca de vestígios desta civilização. Os mais articulados e fluentes deste grupo são o inglês Sir J. Eric S. Thompson e o americano Sylvanus G. Morley, que estabeleceram os parâmetros e alicerces em que a civilização maia esteve estruturada.

Thompson (1898-1975) é considerado o decano da Arqueologia maia. Sua mais importante obra de divulgação The Rise and Fall of Maya Civilization (1954), ainda é muito consultada tanto no meio acadêmico quanto pelo público leigo. Nascido em Londres, lutou na Primeira Guerra Mundial e acabou ferido em combate. Estudou em Cambridge e em 1926 iniciou sua carreira na Arqueologia, analisando hieróglifos e estudando Etnoistória. Escreveu outras obras importantes como The Civilization of the Mayas (1927 e muitas edições posteriores) em que adiciona sua própria projeção de cultura na sociedade maia: "The ceremonial center was the symbol of the small group of priests and nobles (os dois foram muitas vezes indistingüíveis) who ruled the peasants... A 
rough comparison might be made with those old ecclesiastic principalities, such as Salsburg, with the archbishop ruler living in pomp surrounded by this cathedral, administrative buildings, nunneries and friaries, on which were lavished all theart of the age or from the religious and ecclesiastical sides alone, one can thing in terms of an English cathedral close" (Thompson, J. Eric. The Civilization of the Mayas, p.63, 1927).

Podemos perceber, na narração de Thompson, a transferência de uma visão medieval para o âmbito da antiga civilização maia, concepção esta muito corrente na Inglaterra da década de 1920. O discurso assumido de que o colapso da civilização maia foi provocado por um levante camponês segue esta mesma linha de pensamento medievalista que esteve presente e predominou em seu tempo. Thompson também idealizou a civilização maia, preconizando que as relações entre as cidades eram pacíficas e supôs a ausência de guerras, mesmo quando as cenas retratadas nos monumentos e murais indicassem o oposto. Muitas de suas abordagens vieram do contato com os descendentes maias modernos, atribuindo os traços culturais destes a uma contextualização interpretativa da antiga civilização. No entanto, seus trabalhos foram muito bem redigidos e ainda são importantes para a consulta bibliográfica.

Sylvanus A. Morley (1883-1948) também foi precursor na defesa de conceitos que, hoje reunidos, originaram aquilo que chamamos de modelo tradicional da civilização maia, principalmente com a obra The Ancient Maya (1946). Estudou em Harvard e recebeu influência de um outro estudioso da cultura maia, Alfred Tozzer. Associado à Carnegie Institution of Washington em 1945, promoveu expedições nas terras baixas e, entre os anos de 1924 e 1940, dirigiu um extenso trabalho no sítio arqueológico de Chichén Itzá. Embora suas concepções sejam distintas das de Thompson - Morley concebe os centros urbanos como entidades mais complexas - seus modelos para a civilização maia Clássica são similares.

Ambos salientaram as realizações eruditas dos maias e as preocupações religiosas da elite. Assim como Thompson, seus laços de amizade com os maias modernos influenciaram sua 
interpretações a respeito da antiga civilização. Tanto Morley quanto Thompson transferiram seus domínios culturais e de suas elites para a sociedade maia. Thompson, Morley e seus colegas se impressionaram com o desenvolvimento artístico e intelectual dos maias. Documentaram e estudaram suas obras monumentais, principalmente os templos e palácios. Analisaram os inúmeros textos hieroglíficos gravados nas estelas, concluindo que as proezas maias são únicas e incomparáveis.

Com esta visão, não queremos transmitir a Thompson e Morley uma visão reducionista de seus papéis fundamentais no desenvolvimento da Arqueologa maia, tampouco depreciar seus trabalhos, o que seria muito injusto. A nossa preocupação é mostrar como estes estudiosos conceberam a civilização maia, a partir de conceitos revisionistas elaborados pela Arqueologia moderna, o que não anula, em nossa concepção, a importância de suas pesquisas e de suas obras de divulgação.

De acordo com o modelo tradicional, o período que vai de 300 a 900 d.C., conhecido como Clássico, compreende o auge da civilização maia, momento este que até alguns anos era o foco principal de estudo. Este modelo é marcado por um aspecto romântico e baseado em dados oriundos de escavações mal empreendidas e provenientes de sítios de grande extensão. De todas as argumentações formuladas por esta corrente, a mais importante é a em que o período Clássico não teria compreendido sociedades cujo traço principal era o urbanismo. Defenderam a idéia de que os centros urbanos onde havia a maior concentração de templos e palácios teriam sido ocupados somente por sacerdotes, governantes e seus assistentes. A maioria da população teria sido formada por camponeses vivendo em áreas rurais distantes dos centros urbanos. Estes camponeses visitavam estes centros somente em dias de comércio ou em importantes festivais religiosos (a atividade religiosa era praticada somente nos centros urbanos segundo o modelo tradicional), mesmo assim permanecendo pouco tempo neles.

O modelo tradicional atribuiu ausência de urbanismo nas sociedades maias devido às extensas práticas de agricultura. Os maias adotaram um sistema de cultivo chamado coivara (slash- 
and-burn), um método que provoca um desmatamento da área escolhida para o plantio e uma vez seca a vegetação, é cortada e queimada, permitindo a limpeza do solo para o cultivo. Os primeiros arqueólogos defenderam que a prática desta atividade teria sido tão ampla que, após a colheita, o solo necessitaria ser recuperado dos efeitos provocados pela queimada e inviabilizando um plantio subseqüente, o que consumiria toda a área útil necessária para a implantação de um centro urbano. Além disso, o tempo gasto na agricultura inviabilizaria a dedicação a outras atividades, como a criação de um centro urbano. E, complementando, os maias teriam sido consumidores apenas de milho, feijão e abóbora, a tríade que forma o chamado "triunvirato" de sementes do Novo Mundo. Juntos, estes alimentos teriam suprido a maioria dos nutrientes essenciais necessários a sua sobrevivência.

O modelo tradicional forneceu também a idéia de que os sacerdotes consumiram todo seu tempo em previsões esotéricas, estudando o céu e interpretando os presságios, o que hoje podemos chamar de astrologia e adivinhação. Os sacerdotes e seus assistentes (escribas) anotaram os resultados de suas observações astronômicas e cálculos matemáticos em tiras de papel dobrados (códices) e em inscrições hieroglíficas nos murais, confeccionaram vasos policrômicos e gravaram ainda as inscrições nos monumentos, como as estelas. Suas inscrições somente teriam relação com o calendário, astronomia e conceitos religiosos sobre a passagem do tempo e de difícil entendimento. De acordo ainda com este modelo, os maias não registraram eventos históricos ou transações econômicas como os antigos egípcios, sumérios ou babilônios.

Os arqueólogos tradicionais conceberam a cultura maia como teocrática, em que os sacerdotes detinham o poder político. Os sacerdotes teriam governado os centros urbanos. E a partir desta perspectiva, o modelo tradicional defendeu a idéia de pacificidade entre os centros urbanos. Como já mencionado no início deste capítulo, a localização geográfica da civilização maia, proposta por este grupo de estudiosos tradicionais, enfatizou que seu 
isolamento permitisse às sociedades manterem uma cultura homogênea.

Em torno do ano 800 d.C., ainda segundo o mesmo modelo tradicional, os centros urbanos das terras baixas sofreram um processo de declínio, entrando em colapso após um século. Há muitos argumentos para suas causas como o fracasso das práticas de agricultura e um levante da massa camponesa. Como as terras do sul passam a ser abandonadas, as do norte tornam-se mais proeminentes, embora os arqueólogos discordem do momento deste acontecimento. Um grupo de centros urbanos localizado na região Puuc, no oeste das terras baixas do norte, incluindo Uxmal, Sayil e Labná, teria alcançado seu auge no fim do Clássico e entrando em colapso ao mesmo tempo em que as terras do sul.

Segundo J. Eric Thompson e seus colegas, o período Clássico foi anunciado quando os toltecas do México Central invadiram o norte das terras baixas no século $\mathrm{X}$ e conquistaram o centro urbano de Chichén Itzá. Este centro teria florescido durante poucos séculos e controlado toda a região norte, antes também de entrar em colapso.

Sua posição de liderança foi substituída por Mayapán, que liderou uma confederação entre os centros urbanos da península de Iucatã, entre os séculos XIII a meados do XIV. Quando os espanhóis chegaram ao Iucatã, um século depois, o domínio maia consistia de um grande número de cidades independentes, com ausência de um poder centralizado. Segundo Morley e Thompson, a introdução de traços culturais estrangeiros, como a dos mexicanos, teria provocado este processo de "decadência" da civilização maia. As inscrições hieroglíficas cessam, a arquitetura torna-se menos imponente e seu estilo artístico apurado desaparece. À época da ascensão de Mayapan, no Pós-Clássico (1250-1520 d.C.), a cultura maia já havia perdido seus dias de glória tão vigentes no Clássico. Thompson ainda salienta que os maias que os espanhóis encontraram estavam longe da sua magnificência cultural do século VIII.

Em suma, o modelo tradicional enfatizou os antigos maias como um povo de realizações únicas, não somente em seus traços culturais, mas em seu curso geral de desenvolvimento alcançado 
nos tempos clássicos. Argumentaram ainda que a floresta tropical, isolada, teria produzido um meio de convívio pacífico e harmonioso entre as cidades, o que permitiu, de modo incomparável às demais civilizações, suas realizações culturais e artísticas que ainda hoje podemos observar.

\section{Novas perspectivas sobre o Pré-Clássico}

O modelo tradicional viu o Pré-Clássico como uma sociedade formada por camponeses. Hoje, entretanto, sabemos que o surgimento da civilização maia ocorreu bem antes do que é preconizado por aqueles estudiosos. Apesar de Thompson e Morley acreditarem que muitos dos traços notórios do Clássico estiveram presentes pelo menos nos anos iniciais do Pré-Clássico Tardio, cada vez mais os estudos comprovam esta premissa. As maiores transformações neste ponto de vista vieram com as escavações no sítio de Tikal, Guatemala, em sua fase correspondente ao Pré-Clássico.

Projetos desenvolvidos nas décadas de 1970 e 1980 mostraram que os centros urbanos começaram a se desenvolver pelo menos em 300 a.C. e não em 300 d.C. como vinha sendo sustentado até então (Andrews IV e Andrews V, 1980; Pendergast, 1981; Robertson e Freidel, 1986; Hammond, 1987). A dificuldade em se estabelecer parâmetros para o Pré-Clássico repousa no fato de que os maias sempre prosseguiram suas construções sobre as estruturas mais antigas, o que dificulta a recuperção de informações sobre este período, provocando uma lacuna no processo da compreensão arqueológica.

A partir destes projetos, hoje sabemos que o Pré-Clássico recua do ano de 800 a.C. pelo menos quatro séculos. Segundo E. Willys Andrews V (1980), dois grupos teriam se estabelecido nas terras baixas do sul, vindos de locais distintos. Um deles é um povo de língua maia, vindo das terras altas do norte da Guatemala e se fixado na porção nordeste das terras baixas do sul em sítios como Cuello, na atual Belize. O outro grupo, que não falava a língua maia, teria vindo das terras altas de Chiapas, México, e se 
fixado no vale do rio Pasión em sítios como Altar de Sacrificios e Seibal. Estes grupos teriam vivido em pequenas vilas, tendo o milho como principal atividade de subsistência.

Em torno do ano 600 a.C. aproximadamente, os maias começaram a se expandir para áreas até então não ocupadas nas terras baixas. Entre 600 e 300 a.C., a população das terras baixas teria aumentado consideravelmente, provocando o surgimento de novas vilas. Os primeiros exemplos de arquitetura pública, encontrada em Uaxactún, como as plataformas de função doméstica ou religiosa, provavelmente datam deste período. Ainda segundo Willys $\mathrm{V}$, a população crescente poderia ter alimentado os sacerdotes e fornecido a mão-de-obra necessária à construção de estruturas públicas. $\mathrm{O}$ crescimento certamente teria se prolongado com muita rapidez e os maias, já no Pré-Clássico de 300 a.C. a 300 d.C., teriam a habilidade de mobilizar um grande número de pessoas para empreender suas construções, além de alimentar e sustentar toda a sociedade, tendo ainda criado motivos iconográficos complexos e participado das redes de comércio à longa distância.

No fim do Pré-Clássico, a competição por terras, povos e recursos teria provocado guerras entre as cidades, como defende Webster (1977). Afirma, desse modo, que os fossos e parapeitos em torno de Becán teriam servido como proteção contra as incursões militares de outros centros urbanos.

Para Sabloff, a natureza da guerra na civilização maia é ainda motivo de constantes debates, e um fator para ser estudado, uma vez que seus vestígios podem ser identificados nos sítios (Sabloff, 1971). Acredita ainda que os conflitos tivessem forçado as pessoas a se agruparem em busca de segurança. A elite nos centros urbanos poderia ter incitado a migração para as cidades no intuito de se obter uma mão-de-obra mais ampla além de forças militares. Por sua vez, os centros urbanos requereram uma maior infraestrutura e organização social a fim de fornecer e distribuir alimentos aos trabalhadores urbanos, assim como empreender construções defensivas. 


\section{O Clássico e as atuais concepções}

De um ponto de vista atual, podemos considerar que o período compreendido pelo Clássico vai de 300 a.C. a 1250 d.C., com a ascensão de Mayapán (Sabloff, 1994). Como já salientado, as características do Clássico como as primeiras inscrições hieroglíficas, a confecção de cerâmica policrômica e a construção de grandes obras arquitetônicas não aparecem simultaneamene neste período, mas já estavam presentes no Pré-Clássico Final; o que jamais se pensou é que estes fenômenos pudessem ter ocorrido antes de 300 a .C.

Sabloff (1994) alerta que a cultura maia do Clássico é muito mais dinâmica como muitos arqueólogos ainda pensam. Os novos dados vêm de um reexame dos resultados de trabalhos de campo empreendidos a partir a década de 1950 e dos avanços nos métodos empregados hoje pelos arqueólogos, como a análise dos artefatos, datação radiocarbônica e análises de solo, flora e fauna.

Aliada a estes fatores, a decifração dos hieróglifos tem fornecido novas visões sobre o comportamento da elite governamental do Clássico. Ainda segundo Sabloff, as maiores inovações arqueológicas vêm de novas técnicas de sensores remotos e uma metodologia mais apurada dos estudos de padrão de assentamento dos centros urbanos.

Um exemplo destas inovações para o estabelecimento de novas teorias para civilização maia veio com o Projeto Tikal da Universidade da Pennsylvania, entre os anos de 1956 e 1970, dirigido por Edwin Shook e William R. Coe (1967). O mapeamento de Tikal, realizado a partir de prospecções e radares teleguiados por satélites, mostra a existência de um centro urbano complexo e não cerimonial como até então se pensava. Com base nestes dados, Tikal ocupa uma área de $63 \mathrm{~km}$ quadrados e não de 16 quilômetros, como se supôs, e sua população chegou a 60.000 durante Clássico Final, ao contrário dos 10.000 supostos pelos arqueólogos do modelo tradicional.

Outro momento importante para o estudo da civilização maia veio com a adoção de análises de fotos aéreas registradas nas décadas de 1970 e 1980, contribuindo significativamente para o 
entendimento da natureza de sua agricultura. A aerofotometria revela a presença de terraços e campos elevados para o cultivo, evidenciando deste modo, a capacidade dos maias em moldar a terra de acordo com suas necessidades. O mesmo processo revela ainda a existência de áreas com sulcos no solo em campos elevados com objetivo de evitar a inundação da plantação durante a estação chuvosa.

São registrados também canais que não somente drenavam a água excessiva para as áreas secas, como também traziam nutrientes dos rios para o solo. Ambas as tecnologias permitiam aos camponeses praticar a agricultura intensiva, plantando ano após ano sobre a mesma porção de terra em vez de realizar a substituição de novas terras através do sistema de coivara, visão ainda hoje muito difundida.

Segundo Sabloff, as imagens de satélite e o sistema de radar aerotransportado (side looking airbone radar - SLAR) têm importantes implicações para a Arqueologia. A partir destes instrumentos, os arqueólogos chegaram à conclusão de que os grandes centros urbanos puderam alimentar suas extensas populações, praticando uma variedade de métodos de agricultura intensiva, embora alguns estudiosos questionem a quantidade e a importância destes traços.

Outro aspecto que cai por terra em relação ao período Clássico é a sustentação de que a antiga civilização maia antiga foi alicerçada em uma sociedade pacífica e pacata. Trincheiras, valas, sulcos artificiais e parapeitos foram encontrados a $8 \mathrm{~km}$ em direção sul do sítio arqueológico de Tikal e a $4,5 \mathrm{~km}$ ao norte, próximos de sua vizinha Uaxactún. As trincheiras e parapeitos correm num total de $9 \mathrm{~km}$ de comprimento. Segundo Dennis Puleston, essas barreiras artificiais foram utilizadas para a defesa de Tikal dos ataques de outros centros urbanos (Puleston e Siemens, 1972).

Assim, a guerra pode ter desempenhado um papel importante nos tempos clássicos, muito mais do que se imaginou. Embora conhecidas as pinturas e registros sobre as guerras nos centros urbanos, como as explícitas cenas de ataques e combates pintados nos murais de Bonampak, Chiapas, descobertos na década de 1940, os arqueólogos do modelo tradicional viam tais 
cenas somente como acontecimentos esporádicos e de pouca importância.

Como exemplo, J. Eric Thompson assim demonstra o clima de harmonia que, segundo ele, predominava na sociedade maia: "Maya philosophy is best summarized in the motto, 'Nothing in excess', wich was inscribed over the temple of Delphi. Harmonious living, moderation, and a full comprehension of that spirit of toleration for the foibles of one's neighbors contained in the expression 'live and let live', characterize the present day Maya" (Thompson, J. Eric. The Rise and Fall of Maya Civilization, p. 88, 1954).

O Clássico também é um período em que estrangeiros invadem alguns centros urbanos maias em que se percebe uma nítida evidência da introdução de novos traços culturais marcados pelos estilos arquitetônicos nestes centros, além da presença de inscrições hieroglíficas nos monumentos que aparentemente não são característicos do Clássico. Em centros urbanos como Quiriguá, Dos Pilas, Altar de Sacrificios e Seibal, foram encontrados fortificações em torno de suas áreas. Estudos baseados em estilos cerâmicos e em inscrições hieroglíficas indicam que Seibal foi dominada por uma elite estrangeira que depôs os governantes maias (Adams, 1971).

Pelo fato de este fenômeno ter ocorrido nos fins do Clássico, os primeiros arqueólogos não interpretaram estes traços como característicos do mesmo período. No entanto, as incursões militares indicam que as invasões são um dos processos complexos que levaram ao "colapso" de muitos centros urbanos das terras baixas do sul no século IX. Para Webster (1977), a guerra é uma variável no desenvolvimento político e social dos maias das terras baixas, assim como também no aparecimento de muitas civilizações. A guerra teria sido o resultado da pressão populacional que levou à competição por recursos, mão-de-obra e talvez por mercados e mercadorias nas terras baixas desde o início do Pré-Clássico Final (300 d.C.).

Os arqueólogos pertencentes ao modelo tradicional reconheceram que a influência de Teotihuacán, localizada no vale do México, exerceu transformações de grandes proporções no 
âmbito da sociedade maia. No entanto, defenderam que a elite maia possuía traços culturais muito característicos, capazes de rejeitar as influências externas. A questão dos contatos externos refere-se principalmente ao comércio de longa distância entre os maias e as culturas das terras altas do México Central, em ambas as direções.

O modelo tradicional reconheceu que artigos da elite são comercializados durante o período Clássico, mas não explorou os mecanismos que envolveram este complexo bem como suas implicações para as organizações religiosa, econômica, social e política no contexto cultural da civilização. Supõe-se que, desde o período Pré-Clássico Tardio, estas rotas comerciais já estivessem ativas entre os maias das terras altas e os das terras baixas do sul (Macnany, 1989). As similaridades entre as formas de cerâmica entre as terras baixas e o sul das terras altas da Guatemala e El Salvador, no iníco da era cristã, sugerem que as duas áreas mantiveram contato.

As terras altas também teriam comercializado obsidiana, uma rocha vulcânica vítrea utilizada na confecção de ferramentas cortantes além do jade, usado pela elite na forma de braceletes, colares e brincos e considerado um importante símbolo do poder real. Contatos são evidentes, do mesmo modo, entre parte das terras altas da Guatemala, a região de Chiapas, no México, e a costa Pacífica da Guatemala, revelados pelas similaridades no estilo escultural e nas inscrições hieroglíficas, principalmente nos séculos IV e V d.C. em sítios como Izapa. Outros dados indicam também uma forte relação entre Tikal e Teotihuacán, principalmente na arquitetura e cerâmica (Jones et al. 1981). A natureza dos contatos entre as duas sociedades, se econômica, religiosa, militar ou uma combinação de todos estes fatores ainda é muito discutida. Até mesmo a questão de o contato ter sido direto ou indireto ainda está aberta, requerendo muito cuidado ao ser abordado.

Hoje, a maioria dos pesquisadores acredita que estes contatos entre as terras baixas e altas, bem como com México Central não cessam no Clássico. As cidades maias, bem como outras da região do Golfo do México, teriam ocupado o vácuo 
provocado pelo declínio de Teotihuacán. As mercadorias e idéias provavelmente continuaram a ser compartilhadas. Os arqueólogos hoje estão convencidos de que a direção desta influência nem sempre foi exercida do México Central para as terras baixas maias. Os belos murais pintados durante o Clássico Final no sítio centromexicano de Cacaxtla e nas esculturas do mesmo período em Xochicalco indicam uma presença proeminente de figuras com traços maias, como podemos observar no vestuário das personagens ali representadas.

Hoje, os arqueólogos reconhecem a complexidade do mundo Clássico maia. Cada centro urbano não é uma cópia dos demais, mesmo estando em áreas vizinhas e possuindo a mesma tradição. Os recursos locais eram distintos, implicando que as culturas variaram regionalmente, mas possibilitaram uma rede de comércio local através de mercadorias, gêneros alimentícios e artigos de elite.

\section{O colapso das terras baixas do sul sob uma perspectiva revisionista}

Em torno do ano 800 d.C., as cidades maias das terras baixas do sul passam por um desastroso declínio. A arquitetura monumental cessa, as estelas não são mais erigidas e os centros urbanos virtualmente são abandonados. Mas, por que a civilização maia do Clássico entra em declínio no século IX? Embora os primeiros arqueólogos nunca tivessem chegado a um consenso, a maioria das hipóteses repousavam sob o prisma do desastre ambiental, como terremotos, furacões, alterações climáticas, doenças, pragas agrícolas, guerras e esgotamento do solo.

Estas disparidades prevaleceram até o início da década de 1970, quando perspectivas sobre o Clássico estimularam um reposicionamento da questão. A partir de um seminário ocorrido em Santa Fé, Estados Unidos, no ano de 1970, novas idéias foram propostas no intuito de se estabelecer novos paradigmas para a problemática do colapso. Os participantes deste evento chegaram 
à conclusão de que o colapso não deveria ser considerado um fato isolado.

Para entender os processos envolvidos neste acontecimento, os arqueólogos deveriam compreender a natureza das mudanças ocorridas neste processo antes de estabelecer critérios para o estabelecimento das causas do declínio. Foi proposto que a civilização maia deveria ser vista num contexto mais amplo dos eventos culturais que tiveram como palco outras áreas da Mesoamérica e que os arqueólogos deveriam também reanalisar as questões referentes às alterações climáticas que haviam sido sugeridas.

Os pesquisadores discutiram não somente as causas do colapso, mas também buscaram respostas para o porquê da região nunca ter se recuperado. Suas dúvidas basearam-se na constatação de que em outras civilizações historicamene conhecidas, após o colapso, alguma parcela delas retomou parte de seu desenvolvimento. Às vezes, quando as civilizações passavam por este processo, ressurgiam com muito mais vitalidade que outrora e, em outras instâncias, reapareciam com características culturais parecidas com os primórdios de seu desenvolvimento. Neste sentido, um dos mais intrigantes aspectos do colapso maia é sua completa ausência de recuperação nas terras baixas do sul até os dias atuais onde estas regiões contêm uma população muito dispersa.

Os estudiosos que participaram deste seminário notaram que no final do século VIII, a sociedade Clássica maia sofria tensões internas e externas muito fortes. A população havia crescido significativamente e a estratificação social intensificara-se. A elite tornara-se mais rica, poderosa e mais numerosa, tendo expandido sua burocracia. Por outro lado, o espaço para a acomodação da população começou a decair, como pode ser percebido na diminuição de acesso aos locais sagrados.

Pelo fato de a parcela da populacão responsável pela produção de alimentos ter decaído, o sistema de agricultura não mais conseguiu suprir alimentos a toda sociedade. Estudos realizados pelos antropólogos físicos Frank and Julie Saul (em Sabloff, 1994) indicam a presença de desnutrição, a partir dos 
esqueletos, na sociedade maia do século IX, além de um possível aumento do número de doenças durante o mesmo período.

Como conseqüência da escassez de alimentos, a competição entre os centros urbanos teria aumentado e as cidades passaram a intensificar os ataques militares entre si, no intuito de controlar as cidades e provavelmente se apossar de terras. Além disso, os problemas de administração política devem ter-se tornado um grande desafio para a elite, uma vez que tiveram de aumentar a produção e distribuição de alimentos, como também recrutar mais trabalhadores e materiais para o empreendimento de novas construções, além de proteger as cidades que estavam em intenso processo de expansão (Culbert, 1973; Hosler et al. 1977).

Ao mesmo tempo em que as pressões internas intensificaram-se, pressões externas tornaram-se eminentes, principalmente ao longo das fronteiras ocidentais das terras baixas do sul. Os centros urbanos maias da costa do Golfo do México provavelmente atacaram as fronteiras rompendo as rotas comerciais. Exemplos deste processo, como já salientam em tópicos anteriores, são as incursões militares que conquistaram Seibal e Altar de Sacrificios. Talvez estes sítios tenham servido como bases de ataque a outros centros das terras baixas dos sul.

Parece que os governantes maias desse período estavam cientes de ambos os tipos de tensão e se esforçaram em buscar soluções para o problema. Estes governantes teriam fundado novos centros urbanos, recuperado áreas pantanosas e iniciado maciços projetos de construção. As novas estruturas teriam vinculação com cultos religiosos a fim de apaziguar estas tensões. No entanto, foi necessário utilizar pessoas que se destinavam à agricultura com a finalidade de extrair matéria-prima, cortá-la, transportá-la e talhá-la.

O resultado deste processo teria tornado os maias mais vulneráveis aos desastres, embora os arqueólogos não pudessem definir com precisão que tipo de gatilho teria desencadeado o processo de declínio. Contudo, conseguiram identificar uma série de fatores aos quais os maias estiveram expostos.

Os estudiosos mantiveram a concepção de que o sistema de agricultura maia teria levado a uma degradação severa do solo. A 
degradação do meio-ambiente é uma das razões pelas quais as terras baixas do sul não se recuperaram após o colapso. Estudos ambientais têm indicado uma intensa erosão na época do colapso ligada a um grande desmatamento (Andrews IV y Andrews V, 1980).

A partir do Seminário, os pesquisadores concluíram que, em resposta à ameaça de destruição de suas culturas, os maias escolheram soluções que não resolveram seus problemas. Estas respostas são determinadas pelos traços culturais durante o período Clássico e pela natureza de sua organização sóciopolítico e ideológica.

Com efeito, sem mudanças tecnológicas significativas, o meio-ambiente das terras baixas do sul não pôde suportar uma civilização tão complexa quanto a da sociedade maia do século VIII. Entretanto, novas pesquisas focalizadas nas terras baixas do norte resolveram questões que intrigavam Thompson e Morley: os centros urbanos das terras baixas do norte foram construídos depois ou durante o colapso das terras baixas do sul?

Agora sabemos que a ascensão dos grandes sítios da região Puuc, como Uxmal, Kabah, Sayil, Labná, a florescência de Chichén Itzá e o desenvolvimento da costa leste da Península do Iucatã ocorreram ao mesmo tempo do colapso das terras baixas do sul. Pesquisas em sítios como Sayil mostram que houve fortes similaridades entre os centros urbanos das terras baixas do sul e os do norte, em relação às práticas de agricultura, planejamento urbano, arquitetura, ferramentas, escrita hieroglífica e religião (Killion et al. 1989; Sabloff et al. 1989; Sabloff e Tortellot, 1991; Sabloff e Henderson, 1993).

Em outras palavras, a civilização não entrou em colapso: em vez disso, os centros urbanos de maior poder políticoeconômico das terras baixas do sul perderam sua hegemonia para os centros das terras baixas do norte. Grande parte dos estudiosos que trabalha com esta problemática acreditam que este colapso teve um efeito inverso, uma vez que a sociedade maia tornou-se cultural e politicamente mais complexa, agora geograficamente estabelecida na região Puuc e em Chichén Itzá 
(Culbert, 1973; Sabloff, 1990; Navarro, 2001). Alguns centros urbanos do sul, como Lamanai e Nohmul, localizados em Belize continuaram "vivas" e densamente populadas através do século IX (Pendergast, 1981).

Estudos indicam que as cidades do sul que não sofreram o processo de declínio geralmente estão localizadas próximas às zonas de rotas de comércio que, por sua vez, localizam-se próximas às nascentes dos rios ou em áreas de cultivo de cacau e algodão, considerados produtos valiosos. Novos dados apontam para uma possível razão da ausência de recuperação destes centros urbanos das terras baixas do sul (Sabloff et al. 1975; Sabloff, 1977). As cidades próximas a estes centros e das terras altas do México podem ter tido uma grande demanda de recursos, mercadorias ou colheitas, fazendo com que muitos dos centros das terras baixas não pudessem suprir esta necessidade. Estas mercadorias poderiam ser transportadas através de rotas fluviais ou marítimas e aos arredores das terras baixas do sul.

Dada a severa erosão do solo nas terras baixas do sul, não deve ter havido uma motivação econômica para investir pesadamente na área e fazer dela novamente uma zona de alta produtividade. Desse modo, a sociedade optou pelas terras baixas do norte e, os poucos centros urbanos do sul, como Lamanai e Nohmul, puderam usufruir de uma área agora menos ocupada e tirar melhores proveitos do solo.

\section{O desenvolvimento dos centros urbanos nas terras baixas do norte}

Novos dados sobre epigrafia, arquitetura, padrão de assentamento e rotas comerciais têm preenchido a lacuna em relação às terras baixas do norte que até então padeciam de informações mais concretas. Acredita-se que, nesta região, a civilização Clássica teve um desenvolvimento final entre os anos de 800 e 1000 d .C., o que agora é conhecido como Clássico Final ou Epiclássico. Este desenvolvimento ainda pode ter 
durado até o ano de 1200 d.C., quando Chichén Itzá aparentemente entra em decadência.

Sabe-se, entretanto, que há diferenças estilísticas na arquitetura e cerâmica destes centros se comparados com as do período Clássico, como a introdução de novos estilos em alvenaria, o uso de fachadas decoradas com os desenhos de pedra em mosaico, o crescente emprego de colunas em lugar das abóbodas estendidas sobre as salas, além da substituição da pintura policrômica nas cerâmicas por uma mais simples.

Além disso, pouco antes do Clássico Final, as inscrições hieroglíficas sobre os monumentos deixam de ocorrer. No entanto, segundo Sabloff, as similaridades globais dos planos dos sítios arqueológicos e sua arquitetura, assim como sua organização social, provavelmente permaneceram os mesmos. Este autor salienta ainda que, dentro deste contexto, Uxmal é tão Clássica quanto Palenque.

A população dos sítios da região Puuc, área de colinas do Yucatán onde se aglomerou a maior porção dos centros urbanos das terras baixas do norte, que inclui sítios como Kabah, Sayil, Labná e Uxmal, teria se consolidado em 800 d.C. e desaparecido em menos de dois séculos, o que ainda é alvo de pesquisas. Estudos recentes em Chichén Itzá, reanalisando dados antigos, indicam que houve um mesmo período de ocupação nos sítios Puuc e em Chichén Itzá, o que representa mais que uma seqüência cronológica Puuc-Chichén Itzá, como argumentavam os arqueólogos tradicionais (Cobos, 2003; Navarro, 2007).

A extensão deste período de ocupação ainda é muito discutida entre os pesquisadores, embora hoje grande parte dos arqueólogos concorde que os dois centros foram prosperando e se desenvolvendo juntos, pelo menos em certo espaço de tempo. Infelizmente, o estudo das relações políticas e econômicas entre estes centros ainda é muito incipiente.

Muitos arqueólogos agora estão repensando a divisão temporal convencional em face dos dados arqueológicos desde o início de sua ocupação até o chamado período de Mexicanização ou Tolteca (período em que povos do México Central, em especial os toltecas, teriam invadido e conquistado 
os territórios maias da península do Iucatã, subjugando-os). Este argumento estabelece que Chichén Itzá foi dominada pelos toltecas do México Central por vota do século X d.C.

Devido às poucas escavações empreendidas neste sítio, os argumentos para uma conquista tolteca geralmente baseiam-se em estilos desta cultura encontrados somente sobre a superfície. Assim, os arqueólogos agora admitem que as similaridades das estrututas de Chichén Itzá com as do sítio arqueológico de Tula, capital dos toltecas, são, na verdade, próprias da sociedade maia que esteve direta ou indiretamente em contato com os povos do México Central, provavelmente através do comércio.

O modelo tradicional atribuiu uma divisão espacial para Chichén Itzá, dividindo este centro urbano em dua áreas. A primeira delas é a "Antiga Chichén", com construções maias típicas e, portanto mais antiga; a segunda seria "Nova Chichén", com traços arquitetônicos eminentemente toltecas em decorrência do processo de mexicanização do século $\mathrm{X}$, mais recente. No entanto, novos estudos demonstram que esta divisão é muito mais aparente que real e não sustentada por dados arqueológicos (Andrews IV e Andrews V, 1980; Ashmore, 1981; Sabloff e Rahtje, 1986; Andrews et al. 1988; Andrews, 1990; Cobos, 2003; Navarro, 2001 e 2007).

Muitos arqueólogos hoje acreditam que grande parte dos atributos conhecidos como toltecas em Chichén Itzá já estejam presentes na área maia antes do século $\mathrm{X}$ e não são toltecas ao todo. E mais, a interação entre as terras baixas do norte e o México Central não teria ocorrido somente em único sentido (do México Central para a área maia), mas os maias teriam significativamente influenciado os povos mexicanos, como pode ser percebido nos desenhos em murais de Cacaxtla, no México Central, em que a classe alta maia está nitidamente retratada, portando trajes reais. O que não sabemos é como este contato, direto ou indireto, ocorreu e nem qual sua exata natureza.

Segundo Andrews et al. (1988), Chichén Itzá foi a capital de um Estado que controlou quase toda porção central das terras baixas do norte. O pesquisador acredita que Chichén Itzá 
teve um porto muito importante localizado na Ilha Cerritos, sendo um elo econômico para as áreas de comércio distantes, particularmente o México Central, uma vez que grande quantidade de obsidiana desta região foi encontrada na ilha.

Ainda sobre a análise da distribuição espacial, o estudo da cerâmica e arquitetura de Chichén Itzá leva Andrews a acreditar que este centro urbano pôde ter provocado conflitos com outras entidades políticas sobre a região leste da península, que teve Cobá como um importante centro urbano (Andrews V, 1990).

Chichén Itzá foi um centro religioso de importância difundida em toda Mesoamérica. Mesmo após seu declínio, no século XIII, permanece como um dos principais centros de peregrinação no mundo maia, principalmente por causa de seus templos. Os peregrinos visitavam o local até mesmo no século XVI, principalmente para assistir aos rituais que ocorriam no Cenote Sagrado, conhecido pelos espanhóis como Poço dos Sacrifícios, assunto de que ainda trataremos. Chichén continua sendo um importante centro urbano até aproximadamente 1200 e 1250 d.C., embora estas datas sejam incertas, assim como as razões que levaram a cidade ao declínio.

Devido à falta de prospecções e às suas grandes dimensões, os arqueólogos não possuem muitos dados quanto ao padrão de assentamento do sítio, nem quanto ao número de habitantes que abrigou. Segundo Jeremy A. Sabloff (1994), a necessidade de novas explorações em Chichén Itzá é urgente, salientando que este deve ser o cuidado a ser dado a um sítio de tamanha proporção. Considera ainda que, somente com a queda de Chichén Itzá, o período Clássico maia chega a seu fim, vendo uma urgente necessidade da revisão dos períodos cronológicos da sua ocupação.

O Pós-Clássico (1250-1520 d.C.) é geralmente identificado a partir de dois sítios arqueológicos: Mayapán e Tulum. Explorações no primeiro desses sítios ocorreram na década de 1960, quando os arqueólogos atribuíram ao Pós-Clássico uma clara inferioridade em relação a tudo aquilo que os maias já haviam criado no passado. Mayapán teria liderado uma 
confederação que dominou muitos centros urbanos das terras baixas do norte. Distintivamente dos demais centros urbanos desta área, Mayapán e Tulum estavam cercadas por fortificações. Tulum está estrategicamente situada sobre um penhasco, protegida pelo mar de um lado e pelas fortificações do outro, aspectos estes que ilustram que o Pós-Clássico foi marcado por guerras e conflitos.

Embora os arqueólogos do modelo tradicional tenham culpado o desprestígio da religião como fonte principal da deterioração da cultura maia, ela ainda permaneceria como um elo fundamental na sociedade (Ringle et al. 1998). Entretanto, o culto não estava mais centralizado como antes, uma vez que no Pós-Clássico passou a ser realizado nos santuários familiares mais do que nos suntuosos templos públicos, como se pode perceber em Chichén Itzá.

A partir de documentos espanhóis do século XVI, a ilha de Cozumel teria abrigado um centro comercial durante o PósClássico. Pesquisas demonstram que este traço econômico estendeu-se também para o Pós-Clássico (Rahtje, 1975). Apesar de sua arquitetura e planejamento urbano não terem alcançado - mesmo grau de complexidade dos centros urbanos do Clássico, sua cultura como um todo não pode ser considerada "decadente" como afirmaram os arqueólogos que estabeleceram o tão discutido modelo tradicional para o desenvolvimento da cultura maia.

As prospecções e escavações arqueológicas indicam que a ilha possuiu mais de 30 sítios densamente povoados. Cozumel foi altamente organizada, comportando uma capital, a atual San Gervasio, um sistema de estradas e áreas com funções especializadas, como armazéns. A ilha teria participado inclusive de um complexo sistema de comércio que a posicionou como um centro de comércio à longa distância. A religião tornou-se mais descentralizada, não conseguindo a elite religiosa mobilizar grande montante de trabalhadores para a edificação de templos. Os estudos em Cozumel concluem que a cultura do Pós-Clássico transformou-se ao longo do tempo e não entra em decadência como até então se vinha afirmando. 
Os estudos alertam também para o descaso que tomou conta dos pesquisadores em relação ao Pré e ao Pós-Clássico. Estes projetos demonstram que a civilização maia começa a organizar-se muito antes do tradicional período Clássico. E mais, que a civilização não decai após o suposto "colapso" nas terras baixas do sul, ao redor do ano 800 d.C. Ao contrário, os centros urbanos continuam florescendo nas terras baixas do norte por diversos séculos até a queda de Chichén Itzá, experimentando ainda um desenvolvimento final durante o apogeu de Mayapán, aproximadamente em 1300 d.C.

\title{
Agradecimentos
}

Agradeço ao Dr. Pedro Paulo Abreu Funari (UNICAMP), pela leitura atenciosa do manuscrito e ao Dr. Rafael Cobos Palma (UADY-MÉXICO) pelos comentários sobre os sítios das terras maias do norte do Iucatã.

NAVARRO, Alexandre Guida. The Mayan Civilization: Historiographic and archeological contextualization. História, v.27, n.1, p. 347-378, 2008.

\begin{abstract}
This article deals with the historiographic and archeological contextualization of the Mayan civilization. Its purpose is to trace the profile of the first explorations into archeological sites, the construction of the knowledge created around the first information obtained by Archeology, as well as the diverse research links undertaken in relation to the historical contexts of its time, and the theories used at present by the Mayanists.
\end{abstract}

Keywords: Mayas, Material culture, Historiography, Mexico. 


\section{REFERÊNCIAS BIBLIOGRÁFICAS}

ADAMS, Richard E. W. The Ceramics of Altar de Sacrificios. Papers of the Peabody Museum, Harvard University, vol 63, no. 1, 1971.

ANDREWS, E. Wyllys, IV; ANDREWS, Willys V. Excavations at Dzibilchaltún, Yucatán México. Middle American Research Institute, Tulane University, Publication 48, 1980.

; RINGLE III, William M.; BARNES, Philip J., BARRERA RUBIO, Alfredo; GALLARETA NEGRÓN, Tomás. "Komchén: An Early Maya Community in Northern Yucatán". In: Investigaciones Recientes en el Area Maya, vol. 1, pp. 73-92. XVIII Mesa redonda, Mexico, D.F., Sociedad Mexicana de Antropología, 1984. ; GALLARETA NEGRÓN,

Tomás; ROBLES CASTELLANOS, Fernando; COBOS, Rafael P.; CERVERA RIVERO, Pura. "Isla Cerritos: An Itzá Trading Port on the North Coast of Yucatán, Mexico". In: National Geographic Research, vol. 4, nº. E, pp.196-207, 1988.

ANDREWS, E. Wyllys V, "The Early Ceramic History of the Lowland Maya". In: Vision and Revision in Maya Studies (editado por Peter D. Harrison e Flora Clancy), pp. 1-20. Albuquerque, University of New Mexico Press, 1990.

ASHMORE, Wendy. Lowland Maya Settlement Patterns. Albuquerque: University of New Mexico Press, 1981.

BECKER, Marshall J. "Priests, Peasants and Ceremonial Center: The Intellectual History of a Model". In: Maya Archaeology and Ethnohistory (editado por Norman Hammond and Gordon R. Willey). Austin University of Texas Press, 1979.

BERLO, Janet C.; DIEHL, Richard A. Mesoamerica after the Decline of Teotihuacán, A.D. 700-900. Dumbarton Oaks Research Library and Collection,Washington D.C., 1989.

BRUNHOUSE, Robert L. Sylvanus Morley and the World of the Ancient Maya. Norman: University of Oklahoma Press, 1971.

COBOS, Rafael. The Settlement Patterns of Chichen Itza, Yucatan, Mexico. Ph.D. disertación. Department of Anthropology, Tulane University, 2003.

COE, Michael. Os maias. Editorial Verbo, 1968.

COE, William R. "Tikal: Ten Years of Study of a Maya Ruin in the Lowlands of Guatemala". In: Expedition, vol. 8, no. 1, 5-56, 1965.

Tikal: A Handbook of the Ancient Maya Ruins.

Philadelphia, University Museum, 1967. 
CULBERT, T. Patrick. The Classic Maya Collapse. Albuquerque: University of New Mexico Press, 1973. ; Classic Maya Political History: Hieroglyfic and Archaeological Evidence. Cambridge: Cambridge University Press, 1994.

GANN, Thomas; THOMPSON, J.Eric S. The History of the Maya from the Earliest Time to the Present Day. Nova Iorque: Scribner's, 1931.

GRUBE, N.; Martin, S. Crónica de los reyes y reinas mayas. Planeta: México, 2002.

HAMMOND, Norman. "Sir Eric Thompson, 1898-1975: A Biographical Sketch and Bibliography". In: Social Process in Maya Prehistory; Studies in Honour of Sir Eric Thompson (editado por Norman Hammond), Londres: Academic Press, 1983.

no. 3, pp. 116-133, 1987.

The Earliest Maya. Scientific American, vol. 236,

HOSLER, Dorothy; SABLOFF, Jeremy A.; RUNGE, Dale. "Simulation Model Development: A Case of the Classic Maya Collapse". In: Social Process in Maya Prehistory; Studies in Honour of Sir Eric Thompson (editado por Norman Hammond), pp. 553-590. Londres: Academic Press, 1977.

JONES, Christopher; COE, William R.; HAVILAND, William A. "Tikal: An Outline of Its Field Study (1956-1970) and a Project Bibliography". In: Supplement to the Handbook of Middle American Indians, vol. 1: Archaeology (editores Victoria R. Bricker e Jeremy A. Sabloff), pp. 296312. Austin, University of Texas Press, 1981.

JOYCE, Thomas A. Mexican Archaeology. Nova Iorque: G. P. Putnam's Sons, 1914.

KILLION, Thomas W., SABLOFF, Jeremy A.; TOURTELLOT, Gair; DUNNING, Nicholas P. "Intensive Surface Collection of Residential Clusters at Terminal Classic Sayil A .D 800-1000, Yucatán, México". In: Journal of Field Archaeology, vol. 16, 1989.

KIRCHHOFF, Paul. "Mesoamerica: Sus Limites Geográficos, Composición Etnica y Caracteres Culturales". In: Suplemento da Revista Tlatoani, n 3 , México, 1960.

MARCUS, Joyce. Emblem and State in the Classic Maya Lowlands. Washington D.C., Dumbartun Oaks, 1976.

MCANANY, Patricia A. "Stone-Tool Production and Exchange in the Eastern Maya Lowlands: The Consumer Perspective from Pulltrouser 
Swamp, Belize". In: American Antiquity, vol. 54, no. 2, pp. 332-346, 1989.

MORLEY, Sylvanus G. La Civilización Maya. México: Fondo de Cultura Económica, 1946.

NAVARRO, Alexandre Guida. O Retorno de Quetzalcóatl: o culto à divindade e sua natureza em Chichén Itzá, México. São Paulo: Tese de mestrado, Museu de Arqueologia e Etnologia, Universidade de São Paulo, 2001.

; Las serpientes emplumadas de Chichén Itzá: distribución en los espacios arquitectónicos e imaginería. Tese de doutorado. México: Instituto de Investigaciones Antropológicas, Universidad Nacional de México, 2007.

PENDERGAST, David M. "Lamanai, Belize: Summary of Excavation Results, 1974-1980". In: Journal of Field Archaeolgy, vol. 8, no. 1, pp. 29-53, 1981.

POLLOCK, Harry E. D.; ROYS, Ralph L.; PROSKOURIAKOFF, Tatiana; SMITH, A. Ledyard. Mayapán, Yucatán, Mexico. Carnegie Institution of Washington Publication 619, 1962.

PULESTON, Dennis E.; SIEMENS, Alfred H. "Ridged Fields and Associated Features in Southern Campeche: New Perspectives on the Lowland Maya". In: American Antiquity, vol. 37, pp. 228-239, 1972. RAHTJE, William L. "The Last Tango in Mayapán: A Tentative Trajectory of Production-Distribution Systems". In: Ancient Civilization and Trade (editado por Jeremy A. Sabloff e C. C. Lamberg-Karlovsky), pp. 409-448. Albuquerque: University of New Mexico Press, 1975.

RINGLE, William; GALLARETA NEGRÓN, Tomás; BEY III, George J. "The Return of Quetzalcóatl: Evidence for the Spread of a World Religion during the Epiclassic Period". In: Ancient Mesoamerica, vol 9, pp. 183-232. Cambridge: Cambridge University Press, 1998.

ROBERTSON, Robin A.; FREIDEL, David A. Archaeology at Cerros, Belize, Central America, vol. I: An Interin Report. Dallas, Southern Methodist University Press, 1986.

SABLOFF, Jeremy A.; WILLEY, Gordon R. "The Collapse of Maya Civilization in the Southern Lowlands: A Consideration of History and Process". In: Southwestern Journal of Anthropology, vol. 23, pp. 311336, 1967.

; "The Collapse of Classic Maya Civilization". In: The Patient Earth (editado por John Harte e Robert H. Socolow), pp. 1627. Nova Iorque: Holt, Rinehart and Winston, 1971. 
; SABLOFF, Jeremy A.; RATHJE, William L. A Study of Changing Precolumbian Commercial Systems, Monographs of the Peabody Museum, Harvard University, n 3, 1975. ; SABLOFF, Jeremy A. Old Myths, New Myths:

"The Role of Sea Traders in the Development of Ancient Maya Civilization". In: The Sea in the Pre-Columbian World (editado por E. Benson), pp. 67-88. Washington, D.C., Dumbarton Oaks, 1977.

; Analysis of Fine Past Ceramics. Memoirs of Peabody Museum, Harvard University, vol. 15, no. 2, 1982. ; SABLOFF, Jeremy A.; RATHJE ,William L. Late Lowland Maya Civilization: Classic to Postclassic. Albuquerque, University of New Mexico Press, 1986. ; SABLOFF, Jeremy A.; MCANANY, Patricia A.; $\overline{\text { KILLION, Thomas W. }}$; CARMEAN, Kelli; COBOS, Rafael P.; DORE, Christopher; FAHMEL BEYER, Bernd; LOPEZ VARELA, Sandra; PÉREZ ALVAREZ, Carlos; WURTZBURG, Susan. Archaeology Investigations at Sayil, Yucatán, Mexico, Phase II: The 1987 Field Season. University of Pittsburgh Anthropological Papers n 1989. ; TOURTELLOT, Gair. The Ancient Maya City of Sayil. Middle American Research Institute, Tulane University, Publication 60, 1991.

; HENDERSON, John S. (editores). Lowland Maya Civilization in the Eight Century A .D. Washington, D.C, Dumbarton Oaks, 1993.

; SABLOFF, Jeremy A. The New Archaeology and the Ancient Maya. Nova Iorque: Scientific American Library, 1994. SHEETS, Payson D. "Maya Recovery from Volcanic Disasters, Ilopango and Ceren". In: Archaeology, vol. 32, no. 3, 1979.

SMITH, A. Ledyard. Uaxactún, Guatemala: Excavations of 1926-1937. Carnegie Institution of Washington Publication 588, 1950. SPINDEN, Herbert J. A Study of Maya Art. Memoirs of Peabody Museum, Harvard University, vol. 6, 1913.

TAINTER, Joseph A. The Collapse of Complex Societies. Cambridge: Cambridge University Press, 1988.

THOMPSON, J. Eric S. The Civilization of the Mayas. Field Museum of Natural History, Leaflet 25, 1927.

; Grandeza y Decadencia de los Mayas. México:

Fondo de Cultura Económica, 1954. 
WEBSTER, David L. Defensive Earthworks at Becán, Campeche, Mexico. Middle American Research Institute, Tulane University, Publication 41, 1976.

; "Warfare and the Evolution of Maya Civilization". In: The Origins of Maya Civilization (editado por Adams, R. E. W.), pp. 335-372. Albuquerque, University of New Mexico, 1977.

\section{NOTAS}

${ }^{1}$ Utilizaremos a grafia maia, aportuguesada e flexionada, para nos referirmos à civilização; c.f., edição portuguesa do livro de Michael Coe, Os Maias, Editorial Verbo, 1968.

${ }^{2}$ O termo Mesoamérica foi proposto pela primeira vez em 1943 pelo antropólogo Paul Kirchhoff: "Mesoamerica: Sus Limites Geográficos, Composición Etnica y Caracteres Culturales". In Suplemento da Revista Tlatoani, n 3 , México, 1960. O intuito foi descrever as culturas que se desenvolveram no México e América Central através das semelhanças fundamentais observadas a partir de uma caracterização etnológica em termos de área cultural, do registro etnográfico e pós-colombiano e de suas disposições territoriais.

Artigo recebido em 03/2008. Aprovado em 07/2008. 
(20) 